\title{
LOS DIPUTADOS NO ADSCRITOS \\ EN EL LABERINTO: COMENTARIO A LA S.T.C. 159/2019, DE 12 DE DICIEMBRE
}

NON-ATTACHED DEPUTIES IN THE LABYRINTH. COMMENTARY TO S.T.C. 159/2019, OF DECEMBER 12

\section{Esteban Greciet García}

Asamblea de Madrid

Cómo citar / Nola aipatu: Greciet García, E. (2020). Los diputados no adscritos en el laberinto: comentario a la STC 159/2019, de 12 de diciembre. Legebiltzarreko Aldizkaria - LEGAL - Revista del Parlamento Vasco, (1): 142-163.

https://doi.org/10.47984/legal.2020.006

\section{RESUMEN}

El presente artículo glosa la primera sentencia del Tribunal Constitucional español que resuelve un recurso de amparo de un Diputado no adscrito por los derechos y facultades que se le habían atribuido, en cuanto tal, en un Parlamento autonómico, y pone en relación su situación jurídica con las soluciones que los Reglamentos de las Cámaras y la legislación tratan de dar a la desafección ideológica y al fenómeno del transfuguismo, como anomalía de la relación de representación política.

\section{PALABRAS CLAVE}

Diputado no adscrito, transfuguismo, Parlamento autonómico, representación política, participación política, derechos fundamentales, limitaciones de ejercicio.

\section{ABSTRACT}

This paper comments the first judgment of the Spanish Constitutional Court that resolves an appeal for protection brought by a Deputy not attached by the rights and powers that had been attributed to him, as such, in an autonomous Parliament, and relates his legal situation with the solutions that the House Rules and legislation try to give to ideological disaffection and the phenomenon of transfuguism, as an anomaly in the relationship of political representation.

\section{KEYWORDS}

Deputy not attached, transfuguism, autonomous Parliament, political representation, political participation, fundamental rights, exercise limitations. 


\section{LABURPENA}

Artikulu honetan Parlamentu autonomiko bateko atxiki gabeko Diputatu baten babes-errekurtsoa ebazten duen Espainiako Konstituzio Auzitegiaren lehen epaia komentatzen da. Epai horretan, diputatu horri esleitu zitzaizkion eskubide eta ahalmenenei buruz tratatzen da. Bestalde, ebazpen horrek bere egoera juridikoa lotzen du Ganberen erregelamenduek eta legeriak desafekzio ideologikoari eta transfuguismoaren fenomenoari eman nahi dizkieten irtenbideekin, ordezkaritza politikoaren harremanaren anomalia gisa.

\section{GAKO-HITZAK}

Atxiki gabeko Diputatua, transfuguismoa, Parlamentu autonomikoa, ordezkaritza politikoa, parte-hartze politikoa, oinarrizko eskubideak, jarduteko mugak.

\section{SUMARIO}

I. CRÓNICA DE LA SENTENCIA: UN VIAJE POCO EXITOSO.

II. CONCLUSIONES. BIBLIOGRAFÍA.

\section{CRÓNICA \\ DE LA SENTENCIA: \\ UN VIAJE POCO \\ EXITOSO}

La Sentencia que analizamos aquí acota por primera vez de manera clara cuál es el alcance potencial del status de los Diputados no adscritos en el sistema parlamentario español, después de toda una línea jurisprudencial dedicada a los Concejales de dicha condición -ante lo inédito de la misma en las Cortes Generales, ninguna de cuyas Cámaras la reconoce en su Reglamento- y de otra en la que, partiendo de un fenómeno similar y como recuerda Guillem Carrau (2009: 109)1:

Es conocido que el TC se ha manifestado sobre la admisibilidad de tratamientos distintos en el Reglamento parlamentario en relación con los diputados del Grupo Mixto. Como señala la doctrina, la pérdida de representatividad puede justificar, en efecto, la imposición de limitaciones sobre el estatuto de los diputados que incurran en ella pero no pueden afectar a los contenidos de la representación que individualmente tiene asignada dicho diputado.

1 Este autor (2009: 109-112) pasa revista a diversas resoluciones del Alto Tribunal relativas a la posición en la que habían quedado los Diputados del Grupo Mixto en algunos Parlamentos autonómicos, tales como las Ss.T.C. 214/1990, de 20 de diciembre; 44/1995, de 13 de febrero; y 141/2007, de 18 de junio; a las que habríamos de añadir la S.T.C. 20/2008, de 31 de enero. 
En efecto: los parlamentarios no adscritos ${ }^{2}$, de regulación ya no tan novedosa ${ }^{3}$ en las Asambleas Legislativas de las CC.AA. ${ }^{4}$, asoman en este importante pronunciamiento a través de un periplo de su protagonista que bien podemos calificar de escasamente atendido en sus ambiciones: la pretensión del Diputado recurrente ${ }^{5}$ de la Asamblea de Extremadura $^{6}$ de ver ampliado su estatuto ante una serie de resoluciones de la Mesa de esa Cámara que reputaba excesivamente restrictivas de su ius in officium -y aun de otros de sus derechos fundamentales- apenas ha encontrado eco en el Alto Tribunal.

En particular, la Mesa de la Asamblea le atribuía el derecho a formar parte de la Comisión por él elegida, le reconocía legitimación para presentar las iniciativas de titularidad estrictamente individual y le concedía un turno en los debates de "especial relevancia”. Este va a ser uno de los principales puntos de controversia, dado que el órgano rector se verá obligado a aclarar el significado de esa expresión, que se erige en concepto jurídico indeterminado que adquiere concreción en la aplicación de la norma: se considerarán tales el debate de presupuestos, el de orientación política general del Gobierno, los monográficos y aquellos en que se sustancie la relación fiduciaria de la Cámara con el mismo, como la cuestión de confianza y la moción de censura; y se

2 "... lo cierto es que, a diferencia de la del concejal no adscrito, esta figura no ha sido objeto de un especial interés por parte de la doctrina más atenta al derecho parlamentario español, una circunstancia que no deja de ser sorprendente si tomamos en consideración el hecho de que la misma, en buena medida, sintetiza las tensiones inherentes a nuestro modelo de parlamentarismo" (Vázquez Alonso, 2017: 312).

3 Como originalidad, Guillem Carrau (2009: 126-127 y 133-139) constata que en la VII Legislatura de Les Corts Valencianes, "Tras declarar el pase a la situación de no adscritos de dos diputadas y un diputado, la Mesa (...), oída la Junta de Síndics, adoptó un acuerdo regulando su esfera de actuaciones parlamentarias en desarrollo de lo dispuesto en el RCV que, a continuación, se procede a describir y creando la figura de la agrupación de diputados no adscritos", novedosa, no prevista en ese Reglamento y acordada por la Mesa "para el caso específico de coaliciones electorales, cuando todos los diputados y diputadas pertenecientes a una misma formación política dejasen de pertenecer, por cualquier causa, a su grupo parlamentario. El acuerdo citado concreta que, para proceder a reconocer la formación de la citada agrupación, deberá existir previa certificación de su pertenencia a la citada formación política", con los derechos y facultades que se les garantizaron expresamente y en cuyo detalle se detiene este autor.

En el supuesto de referencia, "... la Mesa de Les Corts, oída la Junta de Síndics, (...) tuvo por acreditada su pertenencia a una misma formación política y acordó tener conocimiento de la constitución de la Agrupación de Diputados no Adscritos (...). Este «status» de diputado no adscrito se ve «mejorado» con la posibilidad de integrarse en una Agrupación de diputados no adscritos con efectos múltiples (...) o de colaborar con diputados de otros grupos parlamentarios para presentar iniciativas concretas de carácter legislativo o de impulso de la acción de gobierno (...) aunque se ve perjudicado, por ejemplo, respecto a los diputados integrados en grupos parlamentarios en el hecho de que, aunque se integre en la Agrupación de diputados no adscritos, no puede formular preguntas al Presidente del Consell en la sesión de control plenaria, faceta que sí que contempla en otros Parlamentos autonómicos". La solución no dio lugar a más conflictos que los dimanantes de la reorganización y adaptación del trabajo parlamentario, e incluso "podría ser interpretada como una opción de garantía de esta faceta del contenido esencial del ius in officium [el derecho a formar parte de un Grupo Parlamentario en conexión con el ejercicio del mandato representativo en términos equitativos] siempre y cuando no quede vacía de contenido o se considere que se ha insertado en un escalón jerárquico del sistema que no le corresponde".

4 "Hasta la fecha, contemplan esta figura, en términos muy similares a como lo hace el Reglamento del Parlamento andaluz, los reglamentos de los parlamentos de Cataluña, las Islas Baleares, Castilla y León, La Rioja, Extremadura, Navarra, Comunidad Valenciana, Madrid, Castilla-La Mancha, Cantabria y Canarias" (Vázquez Alonso, 2017: 311), a los que hemos de sumar el Reglamento de las Cortes de Aragón de 2017. Puede consultarse un cuadro recopilatorio de estas regulaciones, a modo de sinopsis y necesitado de actualización, en Gilbaja Cabrero (2015: 166).

5 D. Juan Antonio Morales Álvarez causó baja en el Grupo Parlamentario Popular, por abandono voluntario, mediante escrito presentado a la Mesa de la Cámara el 6 de julio de 2018, fecha a partir de la cual se sucedieron los acuerdos de ese órgano rector por él impugnados. El Diputado pasó a liderar en esa Comunidad Autónoma la formación política Vox, que en las elecciones autonómicas celebradas el 26 de mayo de 2019 no obtuvo ningún escaño en la Asamblea extremeña, al no superar la barrera del 5 \% en ninguna de las dos provincias que conforman aquélla (Fuente: https://www.hoy.es/ elecciones/autonomicas-municipales/25000-personas-creido-20190527025659-ntvo.html, enlace consultado el 7 de mayo de 2020).

6 La regulación de este Parlamento parte de unos antecedentes que comenta pormenorizadamente Navarro Méndez (2000: 7-55). 
descartará su participación en otros debates como son los de totalidad, los relativos a los Decretos-leyes y los de las propuestas de impulso y de pronunciamiento del Pleno.

Centraremos nuestro trabajo en este ámbito de las facultades políticas que abarca el derecho del Diputado al ejercicio de su cargo público (art. 23.2 de la C.E. de 1978), que entronca con el de participación de los ciudadanos ex art. 23.1.

El elemento resuelto con más facilidad es, antes de ello, el conexo con la faceta económica y material de ese derecho fundamental, que el Tribunal sigue reputando extramuros de lo que denomina, refiriéndose a su "contenido esencial", el núcleo de la función representativa. Para confirmar ese juicio, el F.J. $5^{\circ}$ de la Sentencia desgrana la ya conocida doctrina sobre tales derechos, en la que cabe registrar pocas innovaciones: simplemente que la garantía de su ejercicio, por la relación entre los dos apdos. del art. 23, "adquiere especial relevancia cuando se trata, como sucede aquí, de representantes parlamentarios", de aparente mayor importancia que la de los miembros de las Corporaciones Locales?

Reconoce la Sentencia la "configuración legal" -en este caso, reglamentaria, para la integración del status del Diputado- con que se desenvuelve el derecho del art. 23.2 y, a resultas de ello, el carácter reaccional del mismo en la defensa frente a las perturbaciones ilegítimas que pueda padecer. Como es común en todos los derechos fundamentales, aquí los órganos parlamentarios vienen obligados a interpretar restrictivamente las normas que "puedan suponer una limitación al ejercicio de aquellos derechos o atribuciones que integran el estatuto constitucionalmente relevante del representante público" y a motivar las decisiones en que las apliquen, así como a tener en cuenta la doble vertiente que, por su faz institucional (art. 10.1), delimita el ius in officium ${ }^{8}$.

El derecho vincula en la aplicación de la norma, aunque también en su creación, y en ambos supuestos se impondrá, bien que de manera dispar, el respeto a principios capitales: si la motivación de esos actos "resulta esencial para llevar a cabo el juicio de proporcionalidad de la diferencia de trato", queda claro que en la elaboración de los Reglamentos ha primado la convicción de que la regulación de los Diputados no adscritos

7 Esto quizá se debe a que el principio de representación cobra su faz más sobresaliente cuando al pluralismo político del art. 1.1 se añade la soberanía popular (art. 1.2) encarnada en los poderes públicos dotados de "verdadera" autonomía, lo que ocurre aun cuando el T.C. es consciente de que tanto su definición de aquel principio como la jurisprudencia en torno a la no adscripción emana justamente de lo acaecido no en los Parlamentos, sino en los Ayuntamientos, llamando, además, a la "necesidad de salvaguardar la naturaleza" de los cargos representativos. En este sentido y como se ha subrayado, "el Tribunal sí ha dejado claro que hay un ámbito de indemnidad del estatuto del parlamentario en todo caso amparado por el artículo 23 de la Constitución. Un ámbito de indemnidad que (...) hay que interpretar que es más amplio cuando se trata de representantes en las cámaras legislativas. Adquirir la condición de diputado no adscrito no puede significar, en este sentido, una desnaturalización de la propia función parlamentaria” (Vázquez Alonso, 2017: 314).

8 Sin perjuicio de lo cual la vía del art. 42 de la L.O.T.C. brinda una tutela eminentemente subjetiva, no un cauce revisor de la legalidad objetiva de los acuerdos que puedan incidir en esa esfera iusfundamental. 
persigue un propósito lícito: penalizar las conductas de transfuguismoº aun la mera desafección con el Grupo Parlamentario de origen ${ }^{10}$, sin que se busque la compaginación de esta idea con la libertad ideológica ${ }^{11}$ que consagra el art. 16.1 de la C.E. ${ }^{12}$. Así y de manera general, como indica Seijas Villadangos (2000: 164 y 182-183):

La reflexión inicial de la que partimos es la constatación del desfase, ausencia de acomodación, entre la realidad política y la realidad jurídica, entre normalidad y normatividad, generada por la práctica del transfuguismo político. A consecuencia de ello, cabría describir inicialmente esta sui generis situación que produce el transfuguismo como «mutación» de los resultados del sistema electoral, en el sentido de que a raíz de las prácticas transfuguistas asistimos a una modificación no formal de dichos resultados, afectando en consecuencia al grado de legitimidad [nosotros diríamos de confianza] con el que los partidos políticos se instituyen como protagonistas del devenir político (...).

Nosotros participamos de que el Derecho sí puede y, consecuentemente, debe dar una respuesta al transfuguismo, siempre y cuando el legislador así lo estime, por la sencilla razón de que la Constitución le habilita a ello. Sin embargo y tal como acertadamente afirma Triepel, «en un análisis jurídico lo político puede ser únicamente instrumento, nunca finalidad». De esta forma no podemos proceder gratuitamente a enarbolar banderas políticas sobre un asta jurídica, sino que previamente hemos de integrar, al más puro estilo smendiano, ese sustrato político en los presupuestos generales jurídicos que provee el ordenamiento.

9 Han resumido las posiciones de diversos autores sobre las conductas de transfuguismo y sus eventuales causas Gilbaja Cabrero (2015: 168) e, igualmente, Calatayud Chover (2000: 239): "Junto al legítimo cambio de orientación ideológica de un representante hay que oponer la no menos infrecuente evolución o cambio, a veces sorprendente, de la orientación ideológica de los partidos políticos o de sus dirigentes. Sin duda, todos recordamos increíbles saltos y evoluciones rapidísimas en tesis y programas de algunas formaciones que podrían llegar a justificar racionalmente algunos casos de transfuguismo. El ejercicio del poder, frente a planteamientos distintos mantenidos desde la oposición, la necesidad de captar a determinados sectores del electorado o la propia coyuntura nacional e internacional han provocado algunos cambios significativos". Entre aquellas causas, Seijas Villadangos (2000: 167-168) enuncia las políticas, las jurídicas y las personales.

10 Dice el voto particular de esta Sentencia que "Lo que no tendría mucho sentido es convertir al voluntariamente no adscrito en un exótico minigrupo individual”. En efecto, parece razonable que la restricción que sufra en sus derechos supere la que puede darse merced a las disposiciones reglamentarias que afectan a la participación de los Diputados del Grupo Mixto, que era el destino "natural” de los tránsfugas y asimilados antes de que se regulara ex novo el estatuto de los no adscritos, primero en el ámbito local y luego en el parlamentario; y ello en un contexto en que, por otra parte, se intenta reconocer progresivamente el papel de los Diputados con independencia de los Grupos y, además, de mayor fragmentación de la representación política. Aun así, "esta figura se compatibiliza con el mantenimiento del Grupo Mixto para partidos que no han obtenido representación suficiente para constituir grupo propio. Esta compatibilización del Grupo Mixto con el Diputado no adscrito es considerada más coherente y adecuada por la doctrina con la finalidad de lograr un tratamiento distinto de los diversos diputados del grupo mixto según su procedencia" (Guillem Carrau, 2009: 123-124).

11 En referencia a los disidentes en los Ayuntamientos, "podría haber motivaciones por parte de alguno/s de esos concejales que no fueran merecedoras de reproche, sino todo lo contrario, si es que entendemos -como resulta, por otro lado, lógico- que la decisión de un concejal de abandonar su grupo político no siempre puede ser considerada una «traición» (término usado en el acuerdo antitransfuguismo), sino consecuencia lógica, por ejemplo, de un distanciamiento del grupo político del programa con el que el partido correspondiente se presentó a las elecciones" (Arroyo Gil, 2019: 351). Con una visión similar, "El buen tránsfuga es aquél que se aparta de la disciplina de partido para no traicionar a sus representados. Es claro que, en este supuesto, la conciencia normal se rebela contra las sanciones que otras veces se propugnan, porque el díscolo aparece como alguien que ha tomado una decisión respetable, y los condenados son los jerarcas del partido, que no se atienen a sus compromisos, a ese 'contrato' firmado con los electores el día en que estos los auparon a determinadas posiciones de poder" (Torres Muro, 2016: 11).

12 Derecho del que es titular el Concejal y todo representante público, "así como del derecho de asociación (art. 22.1 C.E.), del que también forma parte, en su vertiente negativa, el derecho a no asociarse o a abandonar una asociación a la que se pertenece, incluyendo aquí, lógicamente, a los partidos políticos", así como a los Grupos municipales y aun a los Grupos Parlamentarios, "en tanto que reflejo institucional del partido político" (Arroyo Gil, 2019: 354). 
El fenómeno aquí examinado ya venía aconteciendo en el seno de los Entes Locales, según recuerda Arroyo Gil (2019: 349-350), con cita de otros autores:

Por otro lado, y pese a la frecuente identificación que se realiza, lo cierto es que «tránsfuga» y «concejal no adscrito», de acuerdo con la regulación vigente, no son exactamente lo mismo (...) El estatuto jurídico del concejal no adscrito no es fácil de aprehender en sus precisos contornos, pues el mismo se ha configurado, en buena medida, por obra jurisprudencial (entre otras muchas, STC 214/1989, de 21 de diciembre), dado que la LRBRL no contiene una regulación completa de cuáles son sus derechos y facultades, remitiéndose al Reglamento Orgánico de cada municipio. Además, también la legislación autonómica puede contribuir, en el ámbito de sus competencias, a configurarlo.

Con similar orientación, ha recalcado Català i Bas (2018: 20-22 y 30) que:

Algunos autores, cuando hablan de transfuguismo, hacen hincapié en el cambio de partido. Sin embargo, el cambio de partido, ya sea por baja voluntaria o por expulsión es el elemento caracterizador del no adscrito, no del tránsfuga. De hecho, se puede ser tránsfuga desde dentro del propio partido como reconoció la STSJCV 90/2013. En mi opinión, el elemento caracterizador del tránsfuga no es dónde está sino qué vota y en este sentido debe considerarse tránsfuga a aquel cargo que en cuestiones de especial trascendencia rompe la disciplina de voto alineándose con los partidos contrarios al que concurrió a las elecciones. El caso más característico es el cargo que estando en el partido de gobierno apoya una moción de censura de la oposición haciendo caer al gobierno y propiciando que la oposición entre a gobernar. El escaño, dirá el Tribunal Constitucional en repetidas ocasiones, pertenece al cargo representativo, no al partido. Ante ello es extendida la opinión entre nuestra doctrina de que el tránsfuga debe ser castigado con la pérdida del escaño. La desposesión del escaño es de trascendencia y naturaleza más jurídica que política y desde el momento en que son especialmente perjudiciales los efectos jurídicos para el diputado, que es el dueño del escaño, no lo olvidemos, un acto tal puede ser entendido como una "persecución" por el voto emitido, lo que, entiendo, afecta de lleno a la inviolabilidad parlamentaria, cuyo objeto, impedir que las funciones del parlamentario, sus opiniones y votos quedaran mediatizados (STC 51/1985) quedaría claramente desvirtuado. Indudablemente el tránsfuga no es llevado ante los tribunales por lo dicho o votado pero es perseguido políticamente por su propio partido con consecuencias jurídicas evidentes que afectan al artículo 23.1 CE por más que esta actitud suponga una deslealtad con el electorado que puede afectar al derecho de los ciudadanos a participar en los asuntos públicos (...).

No podemos cerrar los ojos ante una realidad evidente: la desposesión del escaño por transfuguismo, por romper la disciplina de voto es una "sanción" con efectos jurídicos que pesará en la libertad de opinión y voto del representante que cuando lleva a cabo esa deslealtad está en el ejercicio de sus funciones parlamentarias. Si se desea esa consecuencia hay que desterrar de nuestra Constitución, el mandato representativo y acabar con el carácter absoluto que nuestra Carta Magna otorga a la inviolabilidad parlamentaria (...). Con tal pretensión se desea introducir en nuestro ordenamiento jurídico, se quiere juridificar, en definitiva, una represalia política, por más que éticamente tengan razón los que defienden tal medida. 
Arruego Rodríguez (2013: 100-101) destaca que la creación de la categoría jurídica -si es que se puede tener por tal- del Diputado no adscrito

... no parece obedecer a una decisión de naturaleza estructural acerca de cuál debe ser el modelo de organización de los órganos representativos. Por el contrario, su introducción poseería un carácter instrumental en tanto que medio para tratar de paliar ciertas situaciones y comportamientos de los representantes políticos que se reputan disfuncionales para el sistema representativo (...). ... como regla general, su incorporación no es, sin embargo, expresión de un cambio de paradigma respecto de los principios con arreglo a los cuales se organizan las cámaras, cuanto una excepción a la pertenencia de los parlamentarios a un grupo parlamentario. Su finalidad sería, básicamente, limitar las posibilidades de participación en las actividades de la asamblea de aquellos representantes que se encontraran en una situación o que hubieran adoptado una conducta contrarias [sic] a su adscripción política originaria.

Por su parte, Guillem Carrau (2009: 101), siguiendo las impresiones de quienes le habían precedido, se muestra muy crítico al abordar el estudio de estos problemas:

Como señala la doctrina, por un lado, la creación de la figura del diputado no adscrito obedece al loable propósito de luchar contra la denostada práctica del transfuguismo político. Por otro, la aparición de esta figura es una manifestación más de la tendencia a la instrumentalización de nuestras Asambleas Legislativas al servicio de los intereses de los grupos parlamentarios en detrimento de su dimensión institucional como órganos del Estado o de la Comunidad Autónoma respectiva.

Regresando a nuestro asunto, aquel núcleo de la función representativa comprende las facultades directamente conectadas con el ejercicio de la potestad legislativa y la de control del Gobierno, dentro de la cual el Tribunal, de modo impropio, engloba la de impulso político, clave en la ratio decidendi de la Sentencia. En consecuencia, el F.J. $6^{\circ}$ se adentra en excluir de aquél los "derechos de contenido económico" -recogiendo la doctrina sentada, por todas, en la S.T.C. 36/2014, de 27 de febrero ${ }^{13}$-, toda vez que al actor se le había atribuido únicamente el cobro de indemnizaciones por asistencia a las sesiones de los órganos a los que perteneciera, denegándole el de las percepciones por el régimen de dedicación exclusiva, que sensu contrario se hallan vinculadas a la adscripción a un Grupo. Para ello se basa en toda su jurisprudencia previa, en la que pueden rastrearse varias premisas interesantes:

- El derecho de acceso al cargo y de permanencia en él da realidad a la relación de representación de los ciudadanos en las Cámaras, sin que pueda identificarse con una prestación de servicios susceptible de una contrapartida económica, dineraria o salarial, al modo de una obligación contractual sinalagmática.

13 En la que el Tribunal se pronunció acerca de la constitucionalidad de la reforma de los arts. 11 y 12 del Reglamento de las Cortes de CastillaLa Mancha, que constreñía las retribuciones de los Diputados de esta Cámara a un régimen prácticamente generalizado de indemnizaciones y "asistencias". 
- La pérdida de los beneficios económicos de los Diputados provinciales no adscritos (S.T.C. 169/2009, de 9 de julio) y de los Concejales con ese status (S.T.C. 246/2012, de 20 de diciembre ${ }^{14}$ ) "no puede considerarse lesiva de los derechos que consagra el art. 23 C.E.”, lo que se hace extensivo a los parlamentarios.

Con respecto a éstos, la asignación cuya percepción prevé el art. 71.4 de la C.E. para los Diputados y Senadores se refiere "exclusivamente a los miembros de las Cortes Generales”: aunque este sistema retributivo haya sido asumido en las Asambleas de las CC.AA. -excepción hecha de aquéllas que contemplan solamente el pago de dietas y/o indemnizaciones-, no es invocable aquel precepto por sus miembros, sino, en su caso, el homólogo de su Estatuto de Autonomía y del Reglamento parlamentario, tal como sucede con los derechos, deberes y prerrogativas de los Diputados de estas Cámaras.

Una vez dado este paso, el F.J. $7^{\circ}$ aborda la justificación de la regulación restrictiva de derechos que, en esos Reglamentos -aquí, sustancialmente, en el art. 39 del de la Asamblea extremeña ${ }^{15}$ (en lo sucesivo, R.A.Extr.)- se da a los representantes no adscritos, lo que descansa sobre la idea central del combate del transfuguismo como finalidad legítima en el plano constitucional ${ }^{16}$ : de este modo, se insiste en configurar un Parlamento potencialmente grupocrático, en cuya vida diaria los Grupos son sujetos colectivos vitales ${ }^{17}$. En este punto, Arruego Rodríguez (2013: 102-104) ha distinguido "dos tipos de «parlamentarios no adscritos»", los «originarios» y los «sobrevenidos»:

14 Dictada al resolver la cuestión de inconstitucionalidad elevada en relación con la Ley 2/2003, de 11 de marzo, de Administración Local de la Comunidad de Madrid -en adelante, L.A.L.C.M.- y que traía causa del conflicto acaecido en el Ayuntamiento de Boadilla del Monte. Podemos encontrar un comentario de esta sentencia en De la Torre Martínez (2014: 124-131, 139-142 y 151-155).

15 El texto, objeto de reforma global por Acuerdo del Pleno de la Cámara de 19 de marzo de 2015, ha sufrido algunas modificaciones posteriores

16 “Pese a que no han faltado oportunas voces doctrinales que han llamado la atención sobre la posibilidad de existencia del 'tránsfuga bueno', subrayando la necesidad de superar ciertos lugares comunes sobre esta cuestión, lo cierto es que la lucha contra el trasfuguismo ha constituido una obsesión compartida en todos los niveles de gobierno y, por supuesto, también en el propio debate académico (...). La traición al grupo corrompe la relación entre representantes y representados y es, por lo tanto, legítimo que dicha corrupción conlleve pérdidas para quien la realiza (...). La garantía de la estabilidad parlamentaria y de la representación resultante de la voluntad de los electores son, en definitiva, finalidades legítimas a las que el reglamento parlamentario puede servir con un importante margen de discrecionalidad” (Vázquez Alonso, 2017: 313 y 316).

17 “Así, la organización grupal de los parlamentarios ya no es sólo derivación principial sino inexcusable exigencia técnica, pues la actividad parlamentaria no puede desarrollarse sino en grupo y con la ayuda facilitada por su infraestructura intra y extraparlamentaria. Desde esta perspectiva se comprende también el carácter que el juez de la Constitución atribuye a los grupos parlamentarios como «entes imprescindibles y principales» en la organización y funcionamiento de las cámaras y en el desempeño de la función parlamentaria" (Arruego Rodríguez, 2013: 112). 
La primera denominación describiría a aquellos representantes que desde el inicio de la legislatura permanecen al margen de la disciplina de los grupos parlamentarios y que, por lo tanto, no se integran en ninguno de los existentes dentro de la cámara (...). En términos generales, es una figura propia de aquellos ordenamientos que, de un modo más o menos expreso, imponen con especial intensidad una clara vinculación entre la adscripción política con la que los diputados electos concurrieron a las elecciones y los grupos parlamentarios en los que se integran en el seno de la asamblea (...).

El segundo supuesto lo constituye (...) aquel representante parlamentario inicialmente integrado en un grupo parlamentario, normalmente el resultante de la unión de quienes comparten su adscripción política, y que a lo largo de la legislatura causa baja en el mismo (...). A su vez, esta segunda posibilidad de calificación como «diputado no adscrito» generalmente puede obedecer a dos motivos: el abandono voluntario por parte del diputado del grupo al que inicialmente pertenecía o su expulsión del mismo; circunstancias que, en su caso, la normativa parlamentaria establece que deberán ser puestas en conocimiento de los órganos de dirección y gobierno de la cámara.

Sobre estos motivos afirma Guillem Carrau (2009: 101) que:

En ambos casos, la pérdida de un diputado o diputada de su adscripción a un grupo parlamentario y su pase a la situación de diputado no adscrito lleva consigo una cadena de consecuencias jurídicas que son susceptibles de afectar al mandato representativo del mismo y a la actividad ordinaria y estructura orgánica de la Institución parlamentaria.

\section{El Tribunal sigue de nuevo lo ya declarado en anteriores resoluciones, y en especial en la S.T.C. 151/2017, de 21 de diciembre ${ }^{18}$ :}

\footnotetext{
18 Esta Sentencia, al resolver la cuestión de inconstitucionalidad planteada en torno al p.3ㅇ del art. 197.1.a) de la Ley Orgánica 5/1985, de 19 de junio, del Régimen Electoral General, redactado por la L.O. 2/2011, de 28 de enero, vino a determinar lo atinente al quórum necesario para proponer la moción de censura en los Ayuntamientos, toda vez que la reforma obedecía al "fin de continuar dificultando las prácticas de transfuguismo, que atacan directamente al corazón del sistema democrático representativo, en tanto que ponen en riesgo la estabilidad municipal y tratan de modificar la voluntad popular (...). De este modo, las medidas legislativas adoptadas en 2011 con el fin de continuar combatiendo el transfuguismo son de sentido contradictorio, pues si por un lado se endurece el llamado «quórum de procedibilidad», por el otro se suaviza el de votación, sin que se alcance bien a comprender por qué” (Arroyo Gil, 2019: 336 -337).

Como recoge este autor de manera resumida (2019: 344), la S.T.C. 151/2017 despeja dicha duda en su F.J. 70: tal medida "... se limita a establecer un reforzamiento del quórum de promoción de la moción de censura sin alterar más allá de ello la dinámica del procedimiento de exigencia de responsabilidad y remoción del alcalde, como acredita señaladamente que no se altere el régimen de mayorías de la fase de votación, momento en el que los concejales proponentes que hayan dejado de pertenecer, por cualquier causa, al grupo político municipal al que se adscribieron al inicio de su mandato no ven limitado su derecho, conservando la facultad de participar en la votación como cualquier otro concejal. En suma, se persigue dificultar su acción de promoción de la moción para evitar incidencias en la estabilidad en la vida municipal, sin añadir a ello, sin embargo, un escenario de restricción o distorsión abierta de su derecho en la fase de decisión". No obstante, la regla no supera el juicio de proporcionalidad stricto sensu que el Tribunal emplea para su enjuiciamiento, y el mismo autor (2019: 360) critica que "el Tribunal trata de diferenciar, como si fuesen cosas perfectamente separables, uno y otro quórum (el de procedibilidad y el de votación), cuando, en realidad, la mayor exigencia del primero condiciona absolutamente la menor gravedad del segundo".
} 
- Ya en la S.T.C. 9/2012, de 18 de enero, al resolver la cuestión planteada en torno al art. 73.3, p. $3^{\text {o }}$ de la L.B.R.L. ${ }^{19}$, la adscripción de los representantes adquirió relieve jurídico, y no meramente político, sobre la base de dos preceptos del Título preliminar de la C.E.: el art. 1.1 en cuanto proclama el valor superior del pluralismo político y el art. 6 al consagrar el papel constitucional de los partidos y su presencia en las instituciones.

- Con todo, se abren paso dos vertientes básicas de esa representación: de un lado, la garantía de igualdad que atañe a aquel núcleo del ius in officium, el cual conserva su dimensión individual; de otro, el mandato libre, igualmente individual, tan soslayado, en puridad, en esas instituciones, y en el que cristaliza el derecho fundamental del art. 23.2. Aquí, otra cita de la reciente jurisprudencia se detiene en la S.T.C. 123/2017, de 2 de noviembre ${ }^{20}$, que actualiza la prohibición del mandato imperativo ex art. $67.2^{21}$ en cuanto tal22: la representación -también la que encarna quien pierde la adscripción- es, asimismo, universal, predicable no ya de todo el cuerpo electoral, sino de toda la sociedad en binomio con el Estado, desempeñando el Parlamento un papel cardinal entre ambos.

19 Ley 7/1985, de 2 de abril, Reguladora de las Bases del Régimen Local -en adelante, L.R.B.R.L.-, en la redacción dada por la Ley 57/2003, de 16 de diciembre. Dispone su art. 73.3 en sus pp. 1ํ, 3, 4ํ y 6ํ․ "A efectos de su actuación corporativa, los miembros de las corporaciones locales se constituirán en grupos políticos, en la forma y con los derechos y las obligaciones que se establezcan con excepción de aquéllos que no se integren en el grupo político que constituya la formación electoral por la que fueron elegidos o que abandonen su grupo de procedencia, que tendrán la consideración de miembros no adscritos (...). Los derechos económicos y políticos de los miembros no adscritos no podrán ser superiores a los que les hubiesen correspondido de permanecer en el grupo de procedencia, y se ejercerán en la forma que determine el reglamento orgánico de cada corporación. Esta previsión no será de aplicación en el caso de candidaturas presentadas como coalición electoral, cuando alguno de los partidos políticos que la integren decida abandonarla (...). Cuando la mayoría de los concejales de un grupo político municipal abandonen la formación política que presentó la candidatura por la que concurrieron a las elecciones o sean expulsados de la misma, serán los concejales que permanezcan en la citada formación política los legítimos integrantes de dicho grupo político a todos los efectos. En cualquier caso, el secretario de la corporación podrá dirigirse al representante legal de la formación política que presentó la correspondiente candidatura a efectos de que notifique la acreditación de las circunstancias señaladas" [la negrita del p.3ํe es nuestra]. Analiza este precepto, con su desarrollo autonómico y local, De la Torre Martínez (2014: 84-109).

20 Esta sentencia anuló, por inconstitucional, la revocación de los Senadores designados por las Cortes Valencianas (Ley autonómica 10/2016, de 28 de octubre, de modificación de la Ley 9/2010, de 7 de julio).

21 Encontramos una de las escasas valoraciones negativas de esta interdicción en Soriano Díaz (2002: 598 y 601): “La prohibición del mandato imperativo de los representantes de la voluntad popular es un residuo histórico que hoy no tiene sentido e incluso opera contra los principios democráticos. Tuvo su razón de ser en el liberalismo cuando el voto era censitario y los partidos políticos aún tenían escasa importancia en la escena política. Porque con esta prohibición se pretendía evitar que el representante se convirtiera en defensor de intereses clientelistas (de quienes le habían votado censitariamente) y no de los intereses de toda la nación; evitar lo que podríamos denominar el clientelismo parlamentario. Sin embargo, hoy, cuando el voto es universal y los partidos políticos constituyen el mecanismo para la participación en las elecciones y para conformar los Parlamentos, la prohibición del mandato imperativo no sólo es contraproducente, sino que origina efectos perversos para el sistema democrático (...). Creo que podríamos asegurar que el Tribunal Constitucional se ha puesto de lado de un formalismo jurídico constitucional contrario a la materialidad funcional de las elecciones y de la designación de los representantes (...). Ha optado por el representante a título individual de la abstracta nación a costa del partido proponente del representante y de sus electores reales. Actitud que comporta una desnaturalización formalista de la realidad jurídica”.

22 “... es (...) una de las bases del sistema de representación, que debe ser respetada en todo caso, si no queremos lanzarnos a la auentura de sustituir el mismo. El estatus del parlamentario puede configurarse - de hecho, se configura en muchos países- sin inmunidad o sin fuero especial, y sería pensable, aunque abiertamente disfuncional, que lo hiciera sin inviolabilidad. No se produciría un cambio de sistema, y seguiríamos hablando de parlamentarismo. No sucede igual con la libertad de mandado [sic], que es un elemento esencial de este. Su supresión conduciría a otro tipo de ¿democracia? Sería un salto cualitativo de enorme importancia” (Torres Muro, 2016: 18). 
- Se impone, en consecuencia, que el juicio de igualdad exija "examinar la proporcionalidad de la diferencia de trato", proyectándose en la triple vertiente de idoneidad, necesidad y proporcionalidad en sentido estricto, si bien el Tribunal, como apuntará el voto particular, no llega a realizar este desglose, sino que se acerca más, como parece propio del principio de igualdad del art. 14 al insertarse en el art. 23.2, al juicio de razonabilidad de esa diferencia, esto es, a determinar si ha devenido en una discriminación constitucionalmente proscrita.

Razonando en coherencia con ello, el F.J. $8^{\circ}$ de esta S.T.C. 159/2019 descarta que la previsión general del Diputado no adscrito "en sí misma considerada" vulnere esa igualdad: resultaría inconstitucional "que algunas de estas medidas legales limitativas entrasen en conflicto con la naturaleza constitucional del cargo representativo", que engloba el mandato libre y la garantía de igualdad en el núcleo mínimo del status o ius in officium de los parlamentarios. Lo dispuesto en el art. 39.2 ${ }^{23}$ del R.A.Extr. no es lesivo, en abstracto, del derecho fundamental de participación en los asuntos públicos “... si el régimen jurídico que se apareja a ella (a esa condición) solo conllevase diferencias de trato que se justifiquen de un modo proporcionado en algún fin constitucionalmente legítimo o que se relacionen con aspectos no nucleares de la función representativa del Diputado" [la negrita es nuestra].

Empero, en la aplicación de ese precepto al caso particular, el Tribunal habrá de verificar si se ha producido vulneración de ese derecho, ciñendo su actuación jurisdiccional a los acuerdos de la Mesa de la Cámara impugnados por el Diputado: el derecho fundamental del art. 23.2 de la C.E. encuentra aquí una tutela exclusivamente subjetiva, aun con consciencia de su dimensión objetiva o institucional, lo que desecha de antemano el planteamiento de la "autocuestión" interna a que autoriza el art. 55.2 de la L.O.T.C., tal como desarrollará el F.J. $10^{\circ}$ de la Sentencia.

En éste, el T.C. no cree pertinente ejercer su misión puramente kelseniana o de depuración del ordenamiento conforme a la Constitución, en lo tocante a la norma reglamentaria discutida; y ello no sin aceptar, en el F.J. $3^{\circ}$, que la novedad del caso, junto con el que las limitaciones del derecho en juego pudieran provenir de una disposición de carácter general, dé lugar a la calificación del recurso como de "especial trascendencia constitucional”. Partiendo de la hipótesis de que el art. $39.5^{24}$ del R.A.Extr. pudiera ser "incompatible con el núcleo de la función representativa que el art. 23 C.E., en su doble

23 “El Diputado que por expulsión o por voluntad propia deje de pertenecer al Grupo Parlamentario al que estuviera adscrito pasará a tener la condición de Diputado no adscrito y no podrá incorporarse a ningún otro Grupo Parlamentario, ni siquiera al Mixto, durante la Legislatura. Asimismo, cesará automáticamente en todos los cargos que ostente en los órganos de la Cámara y no podrá ser reelegido para dichos cargos". individual. No tendrán derecho a las percepciones derivadas de la dedicación exclusiva ni a los derechos económicos propios de los Grupos Parlamentarios, si bien la Mesa de la Cámara garantizará los medios materiales para el desempeño de sus funciones parlamentarias" [la negrita es nuestra]. Sintetiza los derechos y facultades que los Reglamentos parlamentarios atribuyen a los no adscritos Gilbaja Cabrero (2015: 177-178). 
vertiente, garantiza", la Sentencia desestima tal pretensión basándose, nuevamente, en la jurisprudencia previa, dentro de la cual sobresale la S.T.C. 20/2011, de 14 de marzo ${ }^{25}$. Según la misma, y aquí está lo esencial, la igualdad en el estatus de representante político

... se opone a aquellas otras disposiciones que permitan que un Diputado, instrumentando ciertos mecanismos de funcionamiento del órgano representativo para una finalidad que no es la suya propia, alcance o pretenda alcanzar un haz de facultades en el ejercicio de la función representativa que le confiera una posición preponderante respecto de los demás Diputados de la Cámara individualmente considerados [las negritas son nuestras].

Esto es: se asume que el respeto absoluto del derecho fundamental del representante no adscrito, sin límites de ninguna clase, llega a entrañar una suerte de fraude constitucional por dar carta de naturaleza al transfuguismo; y ello sin siquiera reparar en que la no adscripción pueda traer causa de una conducta no necesariamente tránsfuga, aunque así sea en la mayor parte de los supuestos de hecho que se den. La exigencia de proporcionalidad ${ }^{26}$ en las Comisiones de las instituciones representativas -tanto en su composición como en el ejercicio del voto en su seno- podría volverse en contra y en detrimento de los no adscritos sin que ello merezca reproche jurídico: antes al contrario, se conjura de este modo el riesgo de que éstos disfruten de una "posición de sobrerrepresentación"27 que implique una indebida preeminencia respecto de los miembros de la Cámara o Corporación que sí se encuentran adscritos a un Grupo político.

Por lo tanto y en síntesis, la diferencia de trato dispensada a los Diputados no adscritos por el art. 39.5 del R.A.Extr. es acorde, al menos implícitamente, con el test de igualdad, pues preservando sus facultades individuales impide, haya abandonado su

25 La primera de las recaídas en el prolongado conflicto a que dio lugar la situación de los Concejales no adscritos del Ayuntamiento de Majadahonda, también en la Comunidad de Madrid.

26 Como recuerda Arruego Rodríguez (2013: 109-110), "Tal y como ha puesto de manifiesto el Tribunal Constitucional, el concepto de proporcionalidad apela al volumen de cada fuerza política o grupo. Es decir, no puede ser comprendido en términos individuales sino estrictamente grupales, lógica que se proyecta sobre la organización y funcionamiento del órgano representativo", en tanto que la organización en Grupos "significa el establecimiento de una cierta conexión material de sentido entre opción política expresada por el ciudadano y desarrollo de la función inherente al cargo público representativo. Un vínculo (...) parcialmente articulado a través de otorgar relevancia jurídica a la adscripción política del representante y de funcionalizar el mandato representativo respecto de los derechos de participación cuya titularidad ostentan los ciudadanos".

27 Aquí es oportuno destacar el mandato que dirigió a la Asamblea de Madrid la S.T.C. 246/2012: “... el legislador debe articular las disposiciones que procedan para asegurar que, en el caso de que en la corporación municipal existan concejales no adscritos, las comisiones informativas estén integradas no sólo por concejales pertenecientes a los distintos grupos políticos, sino también por concejales no adscritos, siempre de forma proporcional a su representatividad en el Pleno; así como para garantizar que el derecho de los concejales no adscritos a participar en las deliberaciones y a votar en las comisiones informativas en las que se integren no altere la exigencia constitucional de proporcionalidad en la composición y funcionamiento de dichas comisiones", la cual se plasma en "garantizar los derechos de participación política de los concejales no adscritos (en caso de que los hubiere) en dichas comisiones, pero evitando a su vez que se produzca un eventual resultado indeseado de sobrerrepresentación de estos concejales". El mandato fue atendido en el momento en que la Ley autonómica 1/2014, de 25 de julio, modificó el art. 33.3 de la L.A.L.C.M. redactándolo en términos muy parecidos a los del art. 73.3, p. 3ํ de la L.R.B.R.L. 
Grupo de origen o haya sido expulsado de él' ${ }^{28}$, que se le otorgue de resultas una "condición más beneficiosa" que la del "resto de Diputados que, por integrarse en Grupos, ven racionalizado el ejercicio de ciertas funciones inherentes al núcleo de la función representativa", al quedar supeditado el ejercicio real de su ius in officium a la dinámica de los mismos ${ }^{29}$. El T.C. viene a crear una categoría de "abuso de derecho fundamental" con cuya interdicción, por medio de reglas que acoten las facultades de este Diputado capitidisminuido, se "cierra el paso" a su conversión en un free rider, lo que "es plenamente compatible con las exigencias constitucionales derivadas del art. 23 C.E.”.

Antes de superar este plano normativo, el F.J. $9^{\circ}$ ha entrado ya en "las concretas limitaciones del ius in officium asociadas a la condición de Diputado no adscrito y su fundamento", en su núcleo indisponible por el legislador. Se centra la atención en lo que la Mesa $^{30}$ decidió con base en los apdos. 5 y 6 del art. $39^{31}$ del R.A.Extr.; en torno a apartados como este último ha afirmado Arruego Rodríguez (2013: 106) lo siguiente:

Finalmente, hay que destacar las funciones que la mayoría de reglamentos atribuyen a la Mesa de la cámara, oída la Junta de Portavoces, con relación a los derechos de los parlamentarios no adscritos. En este sentido, la pluralidad de previsiones reglamentarias puede ser reconducida, básicamente, a tres modelos no excluyentes. En primer lugar, la atribución de la potestad para resolver todas aquellas cuestiones que pueda suscitar el desempeño por parte de los «no adscritos» de su función representativa. En segundo lugar, su competencia para fijar el procedimiento de intervención de aquéllos en los plenos y en las comisiones. Y, en tercer lugar, y de modo aún más problemático, su capacidad para «concretar» el ejercicio de los derechos que poseen los «no adscritos».

Sobre ello profundiza el citado autor (2013: 123-124) en estos términos:

En este sentido, no parece haber excesivos reparos en que dichos órganos resuelvan puntualmente las cuestiones o problemas que puedan suscitarse con ocasión del desempeño de su labor representativa, pues se trataría, en el fondo, de una función ya amparada por las tradicionales atribuciones que como órganos de dirección y gobierno les corresponden, así como por la propia naturaleza de la función parlamentaria (...). Sin embargo, sí pueden suscitar algunas dudas apoderamientos de carácter más general que ponen en sus manos la «concreción» del ejercicio de los derechos de los «no adscritos»; cuestión que entronca con la doctrina constitucional acerca de

28 Este primer supuesto fue tratado, con arreglo al régimen entonces vigente, por Aguiló i Lúcia (2000: 121-127).

29 Con todo lo que ello implica en punto a la organización del trabajo en la Cámara, la coordinación con sus compañeros y, en particular, el sometimiento a la disciplina de voto, tan polémica si nos atenemos a la libertad de mandato en cuya defensa sale el Tribunal.

30 Órgano que ha de actuar con vinculación a "aquellos principios y reglas que, para cubrir la reserva legal que se proyecta sobre la regulación del derecho fundamental a la participación política (art. 23.2 C.E.), contempla el Reglamento”, así como a los principios sancionados en el F.J. 10ㅇ

31 “6. La Mesa de la Cámara, oída la Junta de Portavoces, decidirá el procedimiento para la interuención en el Pleno y en las Comisiones de los Diputados no adscritos, así como su pertenencia a éstas, si bien respetará en todo caso el derecho a formar parte de al menos una Comisión. Corresponde, asimismo, a la Mesa, oída la Junta de Portavoces, resolver cuantas cuestiones pudieran plantearse en relación con la situación y posibilidades de actuación de los Diputados no adscritos en el marco del presente Reglamento" [las negritas son nuestras] 
la normativa parlamentaria infrarreglamentaria y su capacidad para regular el ejercicio del ius in officium a tenor de la reserva de ley contenida en el artículo $53.1 \mathrm{CE}$, así como con la cuestión más general de las posibilidades de colaboración entre normas legales e infralegales a la luz de aquélla (...).

La aparente diversidad de estos pronunciamientos [del T.C.] probablemente se explique, sin embargo, a la luz de los distintos supuestos de hecho que se encuentran en su base y, sobre todo, de las funciones que, en su caso, cumplen las resoluciones de carácter general y los usos parlamentarios y cuál es su relación con el reglamento parlamentario. En este sentido, es diversa la situación de una norma infrarreglamentaria que al margen de las funciones que le corresponden configura el ejercicio del cargo, que la inclusión en la legalidad reguladora del mismo de una resolución general o de un uso que sirve para suplir una omisión reglamentaria o para coadyuvar en la determinación del significado de un precepto del reglamento.

En los FF.JJ. $11^{\circ}$ y $12^{\circ}$ podemos apreciar cómo la Sentencia bascula del juicio de proporcionalidad hacia uno que pivota más bien sobre la razonabilidad de las restricciones fruto de la aplicación, con "limitado margen" y a quien con redundancia llamaríamos Diputado individual, de una norma que "prevé un haz de derechos (...) que se justifica en evitar que su situación le confiera una posición de preponderancia, lo que le exige valorar las circunstancias concretas de cada caso para contrarrestar tal riesgo" [las negritas son nuestras].

- En cuanto a las iniciativas que podía presentar el recurrente en su calidad de no adscrito, se le había reconocido un cupo, por cada período de sesiones, de una interpelación y una pregunta en Pleno y de una pregunta oral en Comisión a altos cargos y Consejeros del Gobierno regional. En el F.J. 11º esa genérica titularidad o legitimación individual deviene en una acotación del ejercicio del derecho fundada en un "criterio de proporcionalidad" que la Mesa había adoptado al comienzo de la Legislatura, en su reunión de 31 de agosto de 2015, lo que supone una motivación, bien que sucinta.

Ya en el F.J. $12^{\circ}$, el enjuiciamiento se orienta a verificar si el órgano de gobierno ha actuado "de un modo conforme con la naturaleza del concepto de cargo público representativo que incorpora el art. 23.2 C.E.": eso sí, con un grado importante de self-restraint con que el Tribunal se contiene en la vía de amparo, teniendo en cuenta:

... la especial relevancia de la autonomía parlamentaria y, como consecuencia de ello, la facultad que la Constitución reserva a las Cámaras de establecer, interpretar y aplicar las normas que rigen su organización y funcionamiento, pues la ordenación reglamentaria goza de amplia libertad de configuración, siempre que se respete el derecho de los parlamentarios con la representación política, como subraya la S.T.C. 139/2017, de 29 de noviembre (...) [lo que nace de la proyección del art. 23 de la C.E. a todos los Parlamentos y de la valoración de su esfera interna] y también hemos declarado en la S.T.C. 141/2007, de 18 de junio, que «en esta materia nuestra jurisdicción solo puede extenderse de manera excepcional y de conformidad con el principio de mínima intervención, para la estricta garantía de los derechos fundamentales de los parlamentarios» [las negritas son nuestras]. 
En la letra a) de este F.J., el T.C. atiende a esa motivación de la Mesa y aplica otros dos principios de su labor que, a la postre, serán definitivos: los de justicia rogada y congruencia, al constatar que el recurrente "no argumenta nada preciso en defensa de su mera alegación", lo que debe llevar a descartar cualquier atisbo de oficialidad en la tutela del derecho fundamental cuya lesión se denuncia:

... no corresponde al Tribunal «reconstruir de oficio las demandas, supliendo las razones que las partes no hayan expuesto, por ser carga procesal de quien pide amparo constitucional no solamente abrir la vía para que podamos pronunciarnos, sino también proporcionar la fundamentación fáctica y jurídica que razonablemente es de esperar y que se integra en el deber de colaborar con la justicia del Tribunal Constitucional».

De igual modo, al ser abordada la queja de que se le denegaba la formulación de propuestas de impulso y de pronunciamiento en Pleno, en el decisivo F.J. $12^{\circ}$.b) aflorará la distinción entre ambos tipos de propuestas de resolución sin valor de ley. Así, las primeras equivaldrían a las proposiciones no de ley, iniciativas típicas de los Grupos Parlamentarios ${ }^{32}$, como confirma su cupo ${ }^{33} \mathrm{y}$, sobre todo, el que su eventual titularidad y ejercicio individual se supedite al "visto bueno" del Portavoz. Con ello se diferencia el supuesto, por ejemplo, de las peticiones de información tal como las regula el art. 7 del Reglamento del Congreso de los Diputados (R.C.D., de 10 de febrero de 1982), acerca de las cuales la S.T.C. 57/2011, de 3 de mayo ${ }^{34}$, declaró en su día que la exigencia de "firma" del Portavoz, acompañando a la del solicitante,

... no se articula como un requisito material sino como un trámite formal o de procedimiento (...). En consecuencia, la capacidad de iniciativa y la decisión final sobre su presentación no pertenece al Grupo Parlamentario sino que se atribuye y en todo momento permanece en el dominio del Diputado, que es a quien se reconoce individualmente el derecho; esto es, un específico título para el desempeño de su cargo representativo a través de esa facultad, cuya concreción depende únicamente, en principio, de su voluntad.

Es decir: se distingue el "previo conocimiento" por el Grupo, que es lo que significa esa accesoriedad de la firma, del "visto bueno" de su Portavoz, que comporta una manifestación de conformidad, concurrente en pie de igualdad con la del autor de la

32 El art. 209 del R.A.Extr. simplemente enuncia los requisitos de su formulación: "La propuesta de impulso ante el Pleno deberá ser presentada en escrito dirigido a la Presidencia de la Cámara, en el que conste la justificación que la motiva y los aspectos concretos sobre los que se pretende instar la acción del Gobierno, por un Grupo Parlamentario con la firma de su Portavoz o por un Diputado con el visto bueno del Portavoz de su Grupo..." [la negrita es nuestra].

33 Dice el art. 213 que "Los Grupos Parlamentarios, en atención al número de Diputados que los integren, contarán con el cupo de propuestas de impulso ante el Pleno que fije la Mesa, de acuerdo con la Junta de Portavoces, al inicio del periodo de sesiones. En todo caso, todos los Grupos tendrán derecho a incluir, dentro del número que se establezca, hasta un máximo de tres por sesión plenaria".

34 Este caso traía causa de la actividad de un Diputado de un determinado signo político, dotado de cierta autonomía en su actuación e incorporado o adscrito a un Grupo que es correlato de un partido mayor y distinto de aquél al que pertenecía el parlamentario afectado. 
propuesta de impulso: en suma, "una previsión sustantiva" que impide que cualquier Diputado pudiera presentar una a título exclusivamente individual.

En consecuencia, "el acuerdo de la Mesa de denegar al Diputado no adscrito la posibilidad de formular propuestas de impulso no contradice lo dispuesto en el art. 209 en relación al art. 39.5 del Reglamento de la Asamblea. Por otro lado, y teniendo presente que el Diputado no adscrito tiene a su disposición otros medios de control al Gobierno (...), la privación de este tipo de iniciativas no le coloca automáticamente en una situación de desigualdad desproporcionada respecto del resto de Diputados, ..." [las negritas son nuestras], lo cual, sin duda, encierra y deja sin solventar el inconveniente, no meramente teórico, de asemejar la formulación de una propuesta de esta naturaleza a la de una pregunta o una interpelación, que sí son instrumentos de control stricto sensu, con una neta distinción funcional en los planos formal y material.

En cambio, las propuestas de pronunciamiento se aproximarían más a las declaraciones institucionales, aunque con matices ${ }^{35}$. La Mesa de la Asamblea las había calificado como iniciativas de Grupo -no coincidiendo exactamente la regulación del cupo con la de las anteriores ${ }^{36}-\mathrm{y}$ aquí radica la única vulneración del ius in officium:

La primera apreciación de este Tribunal, a partir de estos dos elementos de juicio, es que el art. 217 del Reglamento antes transcrito reconoce a los Diputados considerados individualmente la capacidad abstracta de formular propuestas de pronunciamiento en Pleno. El apartado 11/12 del Acuerdo [de la Mesa] [...], al decir que estas propuestas «son iniciativas de Grupo Parlamentario», desconoce frontalmente este contenido normativo del art. 217 del mencionado Reglamento.

En consecuencia, la Mesa, en la medida que en los acuerdos impugnados niega que el recurrente pueda presentar propuestas de pronunciamiento en Pleno, le está privando de facultades que, además de ser inherentes a la función representativa, aparecen reconocidas en el Reglamento parlamentario a los Diputados considerados en forma individual y, por tanto, atribuidas al Diputado no adscrito por el art. 39.5 del Reglamento [las negritas son nuestras].

No obstante, el voto particular advertirá del posible exceso cometido al permitir que el Diputado pueda presentar, al igual que los Grupos, hasta siete propuestas de esta índole por cada período de sesiones.

35 Según el art. 217, "Son propuestas de pronunciamiento de la Cámara las iniciativas que pueden presentar los Grupos Parlamentarios, a través de sus Portavoces, o los Diputados sobre temas que afecten a los intereses de la Comunidad Autónoma y que tengan por objeto impulsar la actuación de cualquier institución distinta a la Junta de Extremadura" [las negritas son nuestras].

36 El art. 218 dispone que "Para su presentación, calificación, tramitación y debate se estará a lo previsto para las propuestas de impulso, a excepción de los cupos, que serán de un máximo de siete iniciativas por Grupo Parlamentario y periodo de sesiones. La Junta de Portauoces podrá incluir hasta un máximo de dos propuestas de pronunciamiento por sesión plenaria atendiendo a las peticiones motivadas de los Grupos y a la importancia del tema a tratar". 
- Por otra parte, ya habían quedado delimitados positiva y negativamente los debates en los que el Diputado ostentaba derecho a utilizar un turno "menor" de explicación de voto, a continuación de los correspondientes a los Grupos. Siguiendo el parámetro establecido, con tal acuerdo, la Mesa, según dice el F.J. $11^{\circ}$ :

... valora que admitir la participación del Diputado no adscrito en todos los debates plenarios conllevaría una injustificada sobrerrepresentación en relación al resto de Diputados (...). Pero al mismo tiempo aprecia que ese efecto de exceso de representación no sucedería, en el criterio de la Mesa, si se ciñen sus intervenciones a los cuatro tipos de debates plenarios indicados en el acuerdo [...] y a la forma prevista en el previo acuerdo [...] [la negrita es nuestra].

Además, se admitía su derecho a la presentación de enmiendas al articulado de las iniciativas legislativas, aunque se le denegaba la facultad de estar presente en las reuniones de las Mesas de las Comisiones en los que se calificaran y admitieran o no a trámite las mismas y la de participar en las Ponencias, órgano de carácter informal monopolizado, en la práctica, por los Grupos Parlamentarios.

Todo ello remata el perfil de sus posibilidades de actuar uti singuli, si bien aquí el conflicto girará en torno a la exclusión del uso de la palabra en las propuestas de impulso y de pronunciamiento, que la Mesa de la Asamblea también había circunscrito de manera exclusiva a los Grupos, sin dar cabida al Diputado no adscrito al tratarse, además, de debates que ese órgano de gobierno tampoco ha reputado de "especial relevancia".

La Sentencia volverá sobre este extremo en el F.J. $12^{\circ}$.c), y de nuevo se vale de la necesidad de rogación y congruencia, colocando el onus probandi, como no podía ser de otro modo, en el Diputado: el Tribunal sólo podría

... revisar la específica ponderación de la sobrerrepresentación que subyace en la aplicación del art. 39.5 del citado Reglamento (...) si el recurrente cumple con su deber de colaborar con la justicia constitucional mediante una argumentación fundada de la lesión que invoca. Resulta imprescindible que el recurrente motive, con referencia a las circunstancias del caso concreto, que restringir su facultad de uso de la palabra a esos cuatro tipos de debates plenarios le coloca en una situación de infrarrepresentación respecto del resto de Diputados, los cuales, debe recordarse, no tienen el derecho de intervenir en los debates plenarios sino a través de los Portavoces de sus Grupos Parlamentarios [las negritas son nuestras].

Ocurre que la demanda se halla ayuna de fundamento, limitándose a efectuar una serie de alegaciones sin compensar la eventual carencia de motivación de las resoluciones de la Mesa en cuanto potencialmente lesivas del art. 23.2 y sin llegar a hacer 
... una valoración de conjunto que tenga en cuenta que se le concede el uso de la palabra en otros cuatro tipos de debates plenarios (...) ni argumenta porqué [sic] el acuerdo de la Mesa relativo a las intervenciones en los debates resulta desproporcionado y contrario a la igualdad en el ejercicio del núcleo de la función representativa. En fin, no consta (...) un razonamiento que argumentase (...) que la privación del uso de la palabra en esos tres tipos de debates plenarios la somete a una posición de infrarrepresentación respecto del resto de Diputados, por lo que, de acuerdo a la mencionada doctrina constitucional según la que no ha lugar a que este Tribunal reconstruya de oficio las demandas de amparo (por todas, S.T.C. 96/2015), esta tercera y última queja debe ser desestimada.

\section{CONCLUSIONES}

Las resume el F.J. $13^{\circ}$ : se estima parcialmente la demanda de amparo por vulneración del derecho fundamental garantizado en el art. 23.2 de la C.E. en relación con el art. 23.1 sólo en la privación absoluta, al Diputado recurrente, del derecho a formular propuestas de pronunciamiento en Pleno en los términos antedichos. Debe subrayarse, si se comparte la asimilación de esta clase de iniciativas a las declaraciones institucionales, el carácter simbólico de estas y la creciente importancia política que están adquiriendo en las Cámaras a la hora de intentar concitar consensos en temas socialmente relevantes del máximo interés, por lo que tampoco puede desdeñarse el estrecho margen en que la Sentencia da la razón al no adscrito en el reconocimiento de su derecho.

Ahí terminarían los efectos de la S.T.C. 159/2019, por lo demás limitados y casi puramente declarativos, pues la nulidad de los acuerdos de la Mesa en ese solo extremo no lleva aparejada ninguna medida de restablecimiento del derecho vulnerado, al haberse adoptado los mismos en una Legislatura agotada -la IX- de la Asamblea extremeña, siendo así que esta se encuentra ya en la X. No obstante, sí cabe destacar la rapidez con la que el T.C. ha fallado -como viene siendo regla últimamente en los amparos parlamentarios-, aun cuando el valor simplemente doctrinal y pro futuro de la Sentencia traiga causa de que entre la fecha de interposición del recurso -octubre de 2018- y la de su resolución -diciembre de 2019- haya mediado una convocatoria electoral.

Sí merece la pena, en este apartado, acometer un breve ejercicio de comparación entre las pretensiones contenidas en la demanda, las alegaciones de las partes personadas y la parte dispositiva, con base en los FF.JJ. de esta Sentencia:

- El Diputado había llevado a cabo una impugnación prácticamente "universal" de los acuerdos que le afectaban al fijar su estatuto, llegando a alegar la vulneración de derechos fundamentales ajenos al art. 23.2, lo que el Tribunal desestima de plano. 
Así acontece con la supuesta violación del principio de igualdad ex art. 14, que se entiende absorbido en aquel precepto (F.J. $4^{\circ}$.a)), no considerándose, en general, que el régimen aplicado sea discriminatorio en parangón con el de los adscritos -incluyendo a los Diputados del Grupo Mixto ${ }^{37}$ - ni aceptándose la alegación que intenta hacer ver que la configuración reglamentaria de este status jurídico es un "mal" desarrollo del Estatuto de Autonomía ${ }^{38}$, que la convertiría en inconstitucional. Pero, de igual modo, con la de su dignidad (art. 10.1) y su derecho al honor (art. 18.1) por mor del escaño que se le había asignado, aspecto éste en el que el F.J. $4^{\circ}$.b) confirma la irrelevancia constitucional de la ubicación física del Diputado en la sede de la Cámara, ya se trate del Salón de Plenos, ya del despacho que había solicitado, "justificándose que se deje un espacio para visualizar su no pertenencia" a su Grupo de origen, "según nos indica el Letrado de la Asamblea. Por otro lado, las características de los edificios de los que dispone la institución parlamentaria autonómica (...) «hace[n] imposible asignar un despacho individual por Diputado»"39, a lo que no alcanza la garantía de medios materiales que brinda el art. 39.5 del R.A.Extr.

- El Ministerio Fiscal sí se acerca un poco más a lo que el Tribunal finalmente resuelve, al coincidir con sus FF.JJ. en la subsunción del art. 14 en el art. 23.2, en lo relativo a los derechos económicos y la dimensión material del ius in officium, en el no planteamiento de la "autocuestión" y en la ausencia de violación de otros derechos fundamentales, defendiendo la aplicación del art. 39.2 del R.A.Extr. por aquel órgano en razón del "fin legítimo" que se perseguía con las restricciones impuestas al Diputado con diferencia de trato

37 Aquí es oportuno apuntar la tesis de Arruego Rodríguez (2013: 118-119), para quien "La figura del «parlamentario no adscrito» tiene difícil encaje constitucional, pues (...) el concepto constitucional de representación política arroja la imagen de un Parlamento cuyos integrantes están organizados en grupos que son coherentes con la adscripción política con la que concurrieron a las elecciones y fueron elegidos por los ciudadanos o que, en su defecto, se integran en el denominado grupo mixto como garantía no solo de la funcionalidad de la cámara sino, principalmente, como salvaguarda del derecho a la participación política representativa de aquéllos", a lo cual este autor agrega, con cita de la S.T.C. 9/2012, que "el Tribunal Constitucional ha avalado la constitucionalidad de la no integración en el grupo político correspondiente como criterio para establecer un estatuto jurídico diferenciado entre representantes, apelando a sus consecuencias en el equilibrio de fuerzas en el seno del órgano representativo, a la alteración que provoca en la representación democrática y a la relevancia jurídica de la adscripción política. Por lo tanto, aunque la adopción de medidas que afecten restrictivamente al estatuto jurídico de aquellos parlamentarios que no forman parte del grupo parlamentario que se corresponde con su adscripción política es legítima, no lo sería, sin embargo, la atribución de la condición de «no adscritos»".

38 Sobre este particular, el art. 18 del Estatuto extremeño-aprobado por LO 1/2011, de 28 de enero- sólo establece que "Los Diputados de la Asamblea, cuyos derechos y atribuciones se completan en el Reglamento de la misma, representan a la totalidad de la región y no estarán sujetos a mandato imperativo". La regulación de los no adscritos ha ido emergiendo en los Reglamentos de las Cámaras sin que precise de la "habilitación estatutaria explícita" que se exigía en el recurso; sólo serían controvertidos aquellos supuestos en que el Estatuto prevé expresamente la obligación de los Diputados de constituirse en Grupos Parlamentarios, lo que acaso impediría dar cabida, sensu contrario, a su no adscripción.

39 El Letrado sostiene "que se adoptó un acuerdo basado en razones organizativas y siguiendo los criterios de actuaciones precedentes, sin ninguna connotación peyorativa" ni de aislamiento. 
con los parlamentarios adscritos; también, en la necesidad de preservar el núcleo de dicho ius en su vínculo con la garantía de igualdad y la libertad de mandato ${ }^{40}$.

Sin embargo, esta parte solicitó, sin éxito, la nulidad de algunos extremos de las resoluciones de la Mesa de la Asamblea: en lo relativo al cupo de iniciativas que podía presentar, "al no haber motivado la Mesa las razones de su determinación”, habiéndose basado en una genérica proporcionalidad y en el acuerdo de 31 de agosto de 2015; y a la exclusión de la participación del demandante en los debates no considerados de "especial relevancia". Aunque no queda del todo claro, el Fiscal exigía una fundamentación más exhaustiva de la actuación del órgano rector en la distinción de la categoría de tales debates, entendiendo incluidos en aquel núcleo los de totalidad y los de los Decretos-leyes, pero sin detenerse ni en las propuestas de impulso ni en las de pronunciamiento.

Por fin, el Letrado de la Asamblea de Extremadura impetraba la inadmisión del recurso por existir un óbice procesal: la falta de agotamiento, por el Diputado, de la vía interna previa ex art. 42 de la L.O.T.C., que el Tribunal no aprecia al reputar firmes los actos impugnados ${ }^{41}$.

En cuanto a las cuestiones de fondo, interesaba su desestimación total al defender que tales acuerdos "respetan el núcleo de la función representativa del Diputado", lo que el Letrado desgrana aduciendo que se ha garantizado la participación del demandante en los órganos de la Cámara -según su versión, con voz y voto en el Pleno, interviniendo en todos los debates de éste "que ha estimado oportunos" y en la Comisión de su elección, y sólo con voz en las

40 De las sentencias constitucionales que se han parado a estudiar este punto cardinal del Estado democrático se ha afirmado que "han dado una respuesta correcta al problema, porque, aunque la prohibición del mandato imperativo pueda parecer un arma mellada e inservible del arsenal de un liberalismo que ya no se corresponde con la realidad de nuestras democracias modernas, en mi modesta opinión esto no es así en absoluto, desde el momento en que es preciso seguir saluando la posibilidad de que, concedido que el papel que representan los partidos, como ya hemos dicho, es fundamental, los electores mantengan una relación directa, y sin mediaciones desmovilizadoras, con los elegidos. No es cierto, contra lo que se ha sostenido, que la libertad de mandato sea algo arcaico, una reliquia de la vieja democracia liberal superada por la nueva democracia de partidos. Precisamente ahora puede representar un papel fundamental en la defensa de espacios de libertad frente a las tendencias oligárquicas que saltan a la vista en nuestros sistemas políticos" (Torres Muro, 2016: 9-10).

41 En síntesis, el recurrente no había instado la reconsideración de los acuerdos de la Mesa conforme al art. 50.5 del R.A.Extr., pero sí había efectuado un "requerimiento de amparo" de sus derechos con arreglo a su art. 19.3, lo que el F.J. 20 de la Sentencia reputa suficiente para admitir el recurso ante esta jurisdicción: la resolución inicial de la Mesa se basaba en el art. 39.6 del mismo R.A.Extr., antes transcrito, y "A lo anterior cabe añadir que, materialmente, la reconsideración se llevó a cabo por la Mesa de la Cámara al resolver el requerimiento de amparo que efectuó el recurrente, (...). Por esta vía se dio al órgano parlamentario ocasión para reexaminar sus anteriores acuerdos que delimitaban las atribuciones del Diputado no adscrito...." 
demás ${ }^{42}$ y la presentación de sus enmiendas a las iniciativas legislativas; e igualmente, "se le ha facilitado puntual información de los acuerdos adoptados por los órganos parlamentarios" y ha recibido "cumplida respuesta a sus solicitudes de información para el mejor cumplimiento de sus funciones parlamentarias".

Acierta el Letrado, por último, en aseverar que el art. 39 del R.A.Extr. impedía que el Diputado no adscrito permaneciera en el régimen de dedicación exclusiva, añadiendo que había percibido, en concepto de dietas e indemnizaciones por asistencia y gastos de transporte, "las cuantías fijadas por la Mesa, oída la Junta de Portavoces", e insistiendo en que el contenido económico de su derecho, tal como concluirá la Sentencia, "no se halla incardinado dentro del núcleo esencial de la función representativa"..

42 Hemos de prestar atención, siguiendo a Arruego Rodríguez (2013: 121), a que "Efectivamente, el T.C. ha afirmado que reconocer a un representante el derecho a participar sólo con voz pero sin voto en las comisiones, lesiona los derechos fundamentales del artículo 23 C.E.; dicha consecuencia se deriva del rol que poseen estos órganos en el proceso decisorio del órgano representativo, en este caso local, con el resultado de que se «entorpece y dificulta la posterior defensa de sus posiciones políticas mediante la participación en el Pleno»", tal como señaló la S.T.C. 20/2011, confirmando con ello la doctrina sentada en la S.T.C. 169/2009. La S.T.C. 159/2019 no aborda este extremo para las Comisiones parlamentarias. 


\section{BIBLIOGRAFIA}

Aguiló i Lúcia, LI. (2000). La expulsión del Grupo Parlamentario. Asamblea. Revista Parlamentaria de la Asamblea de Madrid, 4, 121-127.

Arroyo Gil, A. (2019). La moción de censura al Alcalde a la luz de la jurisprudencia constitucional (Comentario a la STC 151/2017, de 21 de diciembre). Revista Española de Derecho Constitucional, $116,329-363$

Arruego Rodríguez, G. (2013). Sobre la constitucionalidad del «Diputado no adscrito». Revista Española de Derecho Constitucional, 99, 99-124.

Calatayud Chover, D. (2000). Unas consideraciones sobre los tránsfugas en los Parlamentos autonómicos (o la sensación de ser unos incomprendidos). Corts. Anuario de Derecho Parlamentario, 9, 237252.

Català i Bas, A. (2018). La prerrogativa de la inviolabilidad parlamentaria de nuevo en la encrucijada: entre su reafirmación o su desuirtuación. Revista General de Derecho Constitucional, 27, 1-32.

De la Torre Martínez, L. (2014). El estatuto jurídico de los concejales no adscritos. Barcelona: Fundación Democracia y Gobierno Local.

Gilbaja Cabrero, E. (2015). La figura del parlamentario no adscrito. Corts. Anuario de Derecho Parlamentario, 28, 161-186.
Guillem Carrau, J. (2009). Régimen de los Diputados no adscritos y su Agrupación en Les Corts Valencianes. Revista de las Cortes Generales, 77, 97-139.

Navarro Méndez, J. I. (2000). Patología del transfuguismo político: grandes males, pero ¿buenos remedios? (A propósito de la regulación del estatuto de los diputados "no adscritos" en la reforma del Reglamento de la Asamblea de Extremadura, de 29 de marzo de 1999). Revista de las Cortes Generales, 49, 7-55.

Seijas Villadangos, E. (2000). Representación democrática, partidos políticos y tránsfugas. Teoría y Realidad Constitucional, 6 (Dedicado a: La regulación jurídica de los partidos políticos), 163-188.

Soriano Díaz, R. L. (2002). El transfuguismo: estafa política a la voluntad de los ciudadanos. Derechos y libertades. Revista del Instituto Bartolomé de las Casas, 11, 597-609.

Torres Muro, I. (2016). El transfuguismo político. Un elogio (moderado) del tránsfuga. Revista de estudios jurídicos de la Universidad de Jaén. Segunda época, 16, 1-28. https://doi.org/10.17561//rej. n16.a2

Vázquez Alonso, V. (2017). El caso inédito del Diputado no adscrito en el Parlamento Andaluz. Revista Andaluza de Administración Pública, 97, 311-316. 